\title{
THE CURRENT STATUS OF MAPPING IN THE WORLD - SPOTLIGHT ON OCEANIA
}

\author{
John C Trinder \\ School of Civil and Environmental Engineering, UNSW SYDNEY NSW 2052, Australia (j.trinder@unsw.edu.au)
}

\section{Commission IV, WG IV-2}

KEYWORDS: Global Mapping, Digital, Scale, Oceania

\section{ABSTRACT:}

A summary is presented of the results of questionnaires sent to mapping agencies in Oceania, covering Australia, New Zealand and the Pacific Island countries, to investigate the status of mapping in those countries. After World War II, the Australian Federal Government funded the initial small scale mapping of the whole country leading to increased percentages of map coverage of Australia. Mapping at larger scales is undertaken by the states and territories in Australia, including cadastral mapping. In New Zealand mapping is maintained by Land Information New Zealand (LINZ) at 1:50,000 scale and smaller with regular updating. The results of the questionnaires also demonstrate the extent of map coverage in six Pacific Islands, but there is little information available on the actual percent coverage. Overall there are estimated to be an increases in the percentages of coverage of most map scales in Oceania. However, there appear to be insufficient professionals in most Pacific Island countries to maintain the mapping programs. Given that many Pacific Island countries will be impacted by rising sea level in the future, better mapping of these countries is essential. The availability of modern technology especially satellite images, digital aerial photography and airborne lidar data should enable the Pacific Island countries to provide better map products in future, but this would depend on foreign aid on many occasions.

\section{INTRODUCTION}

Konecny (2013) stated that surveys of the status of mapping around the world were carried out in 1968, 1974, 1980 and 1987, the last survey revealing the status of mapping in 1986, 30 years ago. The survey of mapping in Oceania in 1986, of which Australia covers the majority of the area, revealed that $18.3 \%$ of the area had been mapped at a scale of 1:25,000, $24.3 \%$ had been mapped at 1:50,000, 54\% at 1:100,000 and $100 \%$ at $1: 250,000$. The results of the survey presented in this paper will reveal increases in the percentage coverage of most maps scales since 1986.

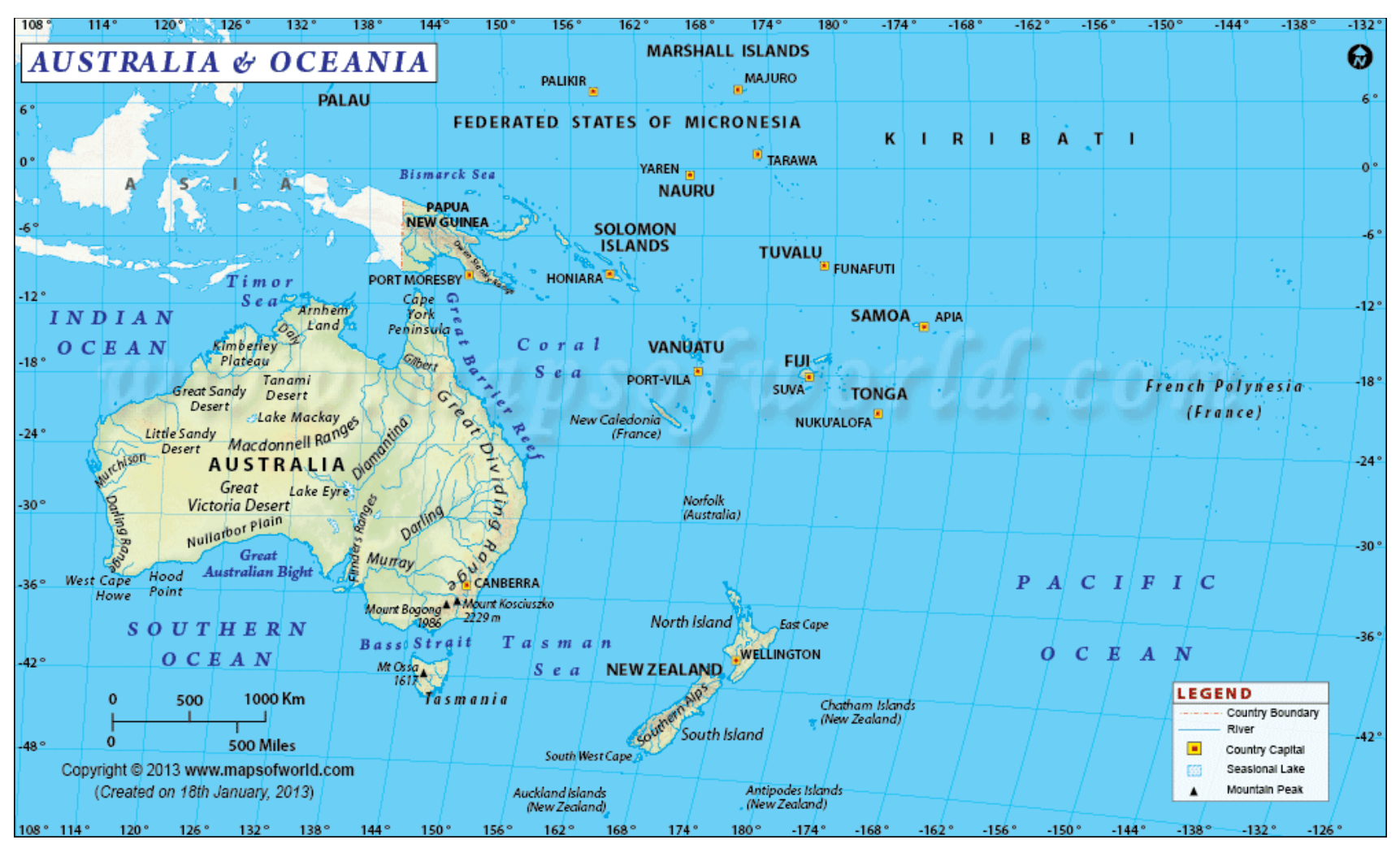

Figure 1 Area covered by Oceania, including Australia, New Zealand, and the Pacific Islands, courtesy WWW.mapsoftheworld.com . 
Oceania is the name of the region consisting of island groups and countries within the central and South Pacific Ocean, spanning over 8.5 million $\mathrm{km}^{2}$. Some of the countries, included in Oceania, as demonstrated in Figure 1, are Australia, New Zealand, Tuvalu, Samoa, Tonga, Papua New Guinea, the Solomon Islands, Vanuatu, Fiji, Palau, Micronesia, the Marshall Islands, Kiribati and Nauru. Oceania also includes several dependencies and territories such as American Samoa, Johnston Atoll and French Polynesia (The Geography of Oceania, 2016).

In order to undertake this survey, government departments responsible for mapping in Australia, New Zealand and Pacific Island countries were approached to complete a questionnaire indicating the types of mapping being undertaken. Responses were received from the federal government and all states and territories in Australia, New Zealand and six Pacific Island countries. In some cases, additional research on the respective web sites was required to extract further information. This paper will reveal that there have been increases in the percentages of coverage at most map scales since the last survey 30 years ago, but there is little information available on the revision cycles of these maps or the actual percentage of coverage in each of the Pacific Island countries.

\section{RESPONSES TO QUESTIONNAIRE - AUSTRALIA \& NEW ZEALAND}

Australia is the world's sixth largest land mass with an area of $7,692,024 \mathrm{~km}^{2}$ of which almost one third is in the state of Western Australia. The smallest state is Tasmania with about $68,000 \mathrm{~km}^{2}$, while the ACT covers $2,358 \mathrm{~km}^{2}$. The population of Australia in 2016 is 23.8 million with about $90 \%$ living along the eastern seaboard. The remainder of the country is sparsely populated since many parts of the country are desert or subject to desert climates. Therefore medium and large scale mapping is only required in limited populated areas of the country. New Zealand has a land area of $268,021 \mathrm{~km}^{2}$ and a population of 4.6 million in 2016. New Zealand's national map coverage is based on medium and small scale mapping.

While Australia and New Zealand are separate administrations, they cooperate on land information issues through ANZLIC (Australian and New Zealand Land Information Council), which coordinates input on land information policy from the jurisdictions in Australia and New Zealand, and develops reviews and approves programs of work including development of or updating guidelines and standards, and projects to achieve its vision. The Intergovernmental Committee on Surveying and Mapping (ICSM) is a committee of ANZLIC, with the role to provide leadership, coordination and standards for surveying, mapping/charting and national datasets.

Australia's administration is based on a federated system comprising the Commonwealth of Australia with many overarching sovereign powers, and six states with their own sovereign powers to manage many operational issues related to administration of day-to-day affairs of the states. The states are: New South Wales (NSW), Queensland, South Australia (SA), Tasmania, Victoria and Western Australia (WA). There are also two territories, Australian Capital Territory (ACT) the administration capital of the country which includes the city of Canberra, and Northern Territory. Territories have their own parliaments, but have less autonomy than the states. The administration of record systems pertaining to land ownership, land tenure, land use and land valuation are undertaken by the respective states and territories (Marwick, 2013). Authority is exercised in New Zealand by the Government of New Zealand, while the administration of mapping is undertaken by Land Information New Zealand (LINZ). Because of the close links between Australia and New Zealand, many aspects of mapping and the management of spatial information are similar. Therefore the answers to the questionnaire for Australia and New Zealand will be discussed together.

The paper will demonstrate the diversity of mapping within Australia which is a function of the administration arrangements around the country. The coverage of medium and large scales is determined by the population density and the number of features in the area. In the Australian Capital Territory, a 1:1,000 map scale is used and the digital details are updated daily. By contrast, in Western Australia where the majority of the population live in the south western corner of the state, only a very small proportion of the state is covered by larger scale maps. Major issues covered by the questionnaire are the map update frequency, methods used for map updating, imagery acquisition, orthophoto production, and lidar and DEM coverage, which vary significantly across the country. Overall the survey reveals that the major map scales covering Australia continue to be the scales of 1:50,000, 1:100,000 and 1:250,000, with limited coverage of larger scales in the populous areas. It is unlikely that the percentage of large scale maps will increase unless there are further significant increases in population densities. New Zealand mapping is based on complete coverage of 1:50,000, 1:250,000 and smaller scales.

\subsection{National Topographic Mapping Coverage}

Question 1: Scales of topographic digital data and/or map products (or series) produced and maintained \& Question 2: Current Age of Existing Geodata

The status of mapping and approximate ages of the maps are presented in Table 1, although in many cases there is limited information available on the ages of maps, and many maps are 30 or more years old. All current mapping in Australia is based on GDA94 (Geocentric Datum of Australia 1994). The mapping of the whole of the country was completed in 1987 with $100 \%$ mapped at $1: 100,000$ and $1: 250,000$, although about half of the 1:100,000 are unpublished products. The only data that is being updated on a regular basis by the Commonwealth government department (Geoscience Australia - GA) is the GEODATA250K, currently series 3, in digital form. Some states/territories are undertaking their own mapping at medium and larger scales with more regular updating as shown in Table 1. It is estimated that $4.7 \%$ of the country has been mapped at scales of $1: 10,000$ and larger, $27.8 \%$ of the country has been mapped at $1: 25,000,46.3 \%$ has been mapped at the scale of $1: 50,000$ and $100 \%$ has been mapped at 1:100,000 and $1: 250,000$.

In New Zealand $100 \%$ coverage is available at 1:50,000, 1:250,000 and smaller scales, based on the New Zealand Geodetic Datum 2000. The data is regularly updated with the average age of the maps less than 5 years.

Indexes of most mapping programs are available on the respective web sites.

\section{Question 3 - Restrictions on Map Data Distribution}

There are no restrictions to access of map data except there may be a charge for cost of supply. In some cases information related to public assets is restricted. 
Table 1 Overall Status of Topographic Mapping in Oceania

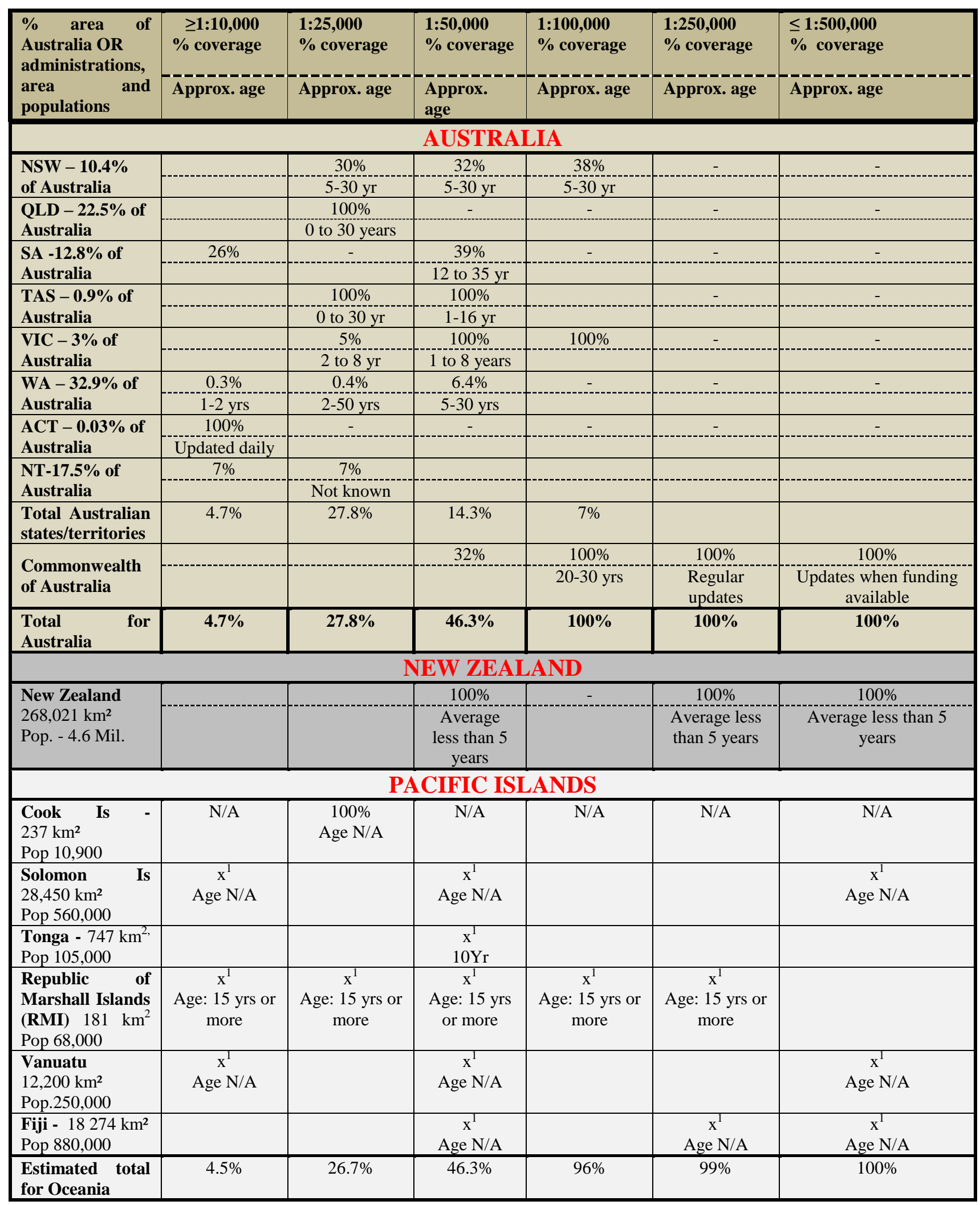

\footnotetext{
${ }^{1}$ Indicates mapping at this scale but the extent of coverage is not available.
} 
Question 4 - Sale of Maps: Are maps sold to the public free of charge and free to Government departments?

Conditions vary for states/territories and federally in Australia. Some states/territories provide digital data free of charge or cost of reproduction, while other states/territories charge the public as well as government departments for supply of data. Charges can be based on per megabyte or per feature. In some cases map products may be priced according to the cost of creating the product. New Zealand data is available free of charge at http://data.linz.govt.nz/ and hardcopies are sold by map retailers.

\section{Question 5 - Updating Strategy}

Generally the update frequency is based on mapping of changed features in the digital data that are reflected in the national or state wide databases. In GA the revision is dependent of funding and staffing for each year. The larger scale map series are updated more frequently, and their updates may feed into smaller scale updates. New Zealand has a strategy for map updating of all scales.

\section{Question 6 - Updating Methodology}

Updating is based on all sources, but mostly from aerial photography, satellite images and third party data sources.

\section{Question 7 - In-house Capabilities of NMAs}

Most mapping is done in-house in Australia and New Zealand, but outsourcing also applies in some states/territories. GA states that outsourcing is dependent on a balance of the complexity of the work to update and the time it takes to complete the work. Some work will be outsourced and others not if the complexity is high and hence internal knowledge would lead to more efficient map production. The time factor is also a consideration: that is, whether the time taken to prepare work packages for outsourcing will be longer than the time taken to complete the activity in-house.

\subsection{National Aerial Imagery Program}

\section{Question 8 - Does a national aerial photography acquisition program exist?}

There is no regular national acquisition of aerial images in Australia or New Zealand, but some Australian states/territories acquire regular coverage of their regions. There is ample domestic capability in Australia for aerial photography, with some state mapping departments having their own facilities. All states/territories record digital imaging while GA also uses analogue images. There is no domestic aerial photography capability in New Zealand.

\section{Question 9 - Satellite Imagery Used by NMA}

There is no national satellite program in Australia or New Zealand and therefore the mapping agencies depend on foreign satellites to source their satellite data, which is used on an as needs basis. The state of NSW acquires satellite imagery of the state on a regular basis.

\section{Question 10 - Use of Radar or Lidar}

Airborne lidar data is acquired extensively on a project basis over specific areas in Australia and New Zealand, such as coastal regions, rivers and urban areas for the determination of DEMs. There is limited acquisition of radar data.

\section{Question 11 - Lidar DEM}

Airborne lidar data at densities from 1 to $8 \mathrm{pts} / \mathrm{m}^{2}$ are being acquired over large areas federally and in some Australian states/territories and New Zealand.

\section{Question 12 - Orthophoto Program}

Digital orthophotos are produced by most Australian states/territories and New Zealand with variable resolutions. Some Australian states/territories acquire $10 \mathrm{~cm}$ pixel size over urban areas and $50 \mathrm{~cm}$ to $75 \mathrm{~cm}$ over rural areas. The coverage of orthophotos is not shown in Table 1 because these details were not included in the responses by most states/territories. However there is an increasing provision of digital orthophotos in Australia. New Zealand acquires digital orthophotos at 1:50,000.

\section{Question 13 - National DEM}

National DEMs are available in Australia at 9 second derived from 1:100,000 and 1:250,000 scale topographic mapping; 3 second and 1 second DEMs derived from the Shuttle Radar Topography Mission (SRTM). Some Australian states/territories have acquired state-wide DEMs; for example NSW and Victoria have acquired $20 \mathrm{~m}$ DEM, while Victoria also has a $10 \mathrm{~m}$ DEM over $80 \%$ of the state and $1 \mathrm{~m}$ DEM over Greater Melbourne Metropolitan Area. Other states/territories have acquired DEMs according to their orthophoto production. A DEM with $25 \mathrm{~m}$ posting is available for New Zealand.

\section{Question 14 - Interest in 3D technology by NMA}

To the question whether the Australia and New Zealand mapping agencies intend to produce 3D urban and rural landscape models and/or product visualization, some responses were yes and others no.

\subsection{National surveying and cadastral coverage}

\section{Question 15 - Licensed Surveyors}

The states/territories are responsible for cadastral surveys in Australia. Therefore, all surveyors who undertake cadastral surveys must be registered in the state in which they undertake the surveys. In New Zealand all cadastral surveyors must be registered nationally.

\section{Question 16 - Responsibility for Cadastral Mapping and Cadastral Map Coverage}

While the Australian states/territories are responsible for assembling the cadastral data the Public Sector Mapping Authority (PSMA) assembles various Australian state's jurisdictional data into national datasets. In New Zealand a seamless digital database is available across the country with the responsibility of the national mapping agency.

\section{Question 17 - Use of Cadastral Maps}

Most common uses of cadastral maps are for land registration, land titles, conveyancing and taxation. In New Zealand they also act as a base map for various functions including resource management and asset management. 


\section{Question 18 - Cadastral Maps and Geodetic Control}

All state cadastral maps in Australia are currently referenced to the GDA (Geocentric Datum of Australia), except ACT which operates on a local coordinate system, but transformations to GDA are available. However, the appropriate geodetic datum is in a transitional stage. A Static Datum GDA2020 will be based on Frame ITRF@2020, while from 2020 a Dynamic Datum will be realised continually.

The New Zealand Geodetic Datum is designed to provide constant unchanging coordinates for features even though New Zealand is continuously moving and deforming under the influence of the Australian and Pacific tectonic plates across which it lies. To do this the datum is moving and deforming along with the New Zealand land mass - it is a "plate-fixed" datum.

\section{Question 19 - Monumentation of Property Boundaries}

The majority of boundaries are monumented in all Australian states/territories and New Zealand.

\section{Question 20 - Updating of Cadastral Maps}

In most Australian states/territories cadastral maps are dynamically updated soon after the survey has been completed and survey plans have been submitted. In New Zealand cadastral data are continuously updated and added to the database electronically, as new surveys and changes to titles are introduced.

\section{Question 21 - Number of Cadastral Employees}

There are approximately 2,500 surveyors in Australia with 90\% in private practice and the remainder in state/territory government employment. There are approximately 600 cadastral surveyors in New Zealand.

\subsection{Organisation}

Question 22 -National Funding for Mapping?

Generally the answer to this question for Australia and New Zealand was yes. The state of Victoria wrote as follows: Government partially funds the framework mapping. Data and product sales subsidise much of the product range. Image acquisition is via a cooperative arrangement with contributions from purchase partners for acquisition of imagery and production of elevation products over specific project areas.

Western Australia (WA) wrote:

There are some opportunities for collaboration with federal agencies (e.g. Geoscience Australia and Bureau of Meteorology). As context, Landgate (the mapping agency in Western Australia) coordinates the Western Australian Land Information System (WALIS) and Community, which is a dynamic partnership of government agencies working with business, education and the general community to manage and promote the State's geographic information. The mission of WALIS is to build networks of people and technology to share land and geographic information, and to continually improve the data's usefulness and accessibility. Hence, WALIS is not a single centralised source of geographic data, but employs processes and strategies to 'capture once, use many times' geographic infromation. This is further embodied in a Location Information Strategy for WA which aims to enhance the use of location information to improve decision making and community outcomes.

\section{Question 23 - Mapping Budget}

The approximate cost of mapping in Queensland (22.5\% of area of Australia) is AUD32 million and in Victoria (3\% of area of Australia) AUD10 million. These figures cannot be extrapolated to the whole of Australia. GA as the National Mapping Agency, has an annual budget of approximately AUD8.5 million for the data acquisition and maintenance programs, and production of standard small scale mapping products. This amount does not include any additional work carried out on customised products for clients and does not include any cadastral work. There were no estimates from New Zealand.

\section{Question 24) NMA staff}

An accurate figure cannot be provided because the tasks of technical staff have become much broader than simply producing maps. GA has a total of 84 staff, $10 \%$ of whom are administration/project management. New Zealand has 13 personnel for the task of topographic mapping.

\section{Question 25 - Legal Status of Mapping}

The federal government's mapping programs are defined by Commonwealth of Australia Administrative Arrangement Orders and Portfolio Budget Statement. Most state/territory governments have no explicit legislative mandate for topographic data collection and management, but this has been an ongoing function of their governments. In New Zealand the cadastral and geodetic functions are mandated by the Cadastral Survey Act 2002, while topographic mapping is a government allocated function.

\section{Question 26 - Form of Map Products Supplied}

The forms vary greatly across the jurisdictions from: $5 \%$ to $40 \%$ - hardcopy

$40 \%$ to $100 \%$ - digital delivered as digital datasets

$40 \%$ to $75 \%$ - digital data downloaded

The percentages are difficult to estimate for New Zealand.

\section{Question 27 - Archival of Geodata}

Some Australian states/territories, the federal department and New Zealand update their archives on a regular basis, eg, every 3 to 6 months, while others update and archive data when changes occur.

\section{RESPONSES TO QUESTIONNAIRE - PACIFIC ISLANDS}

Each of the Pacific Island countries has its own administration which is responsible for mapping and the management of land information.

\subsection{National Topographic Mapping Coverage}

Question 1: Scales of topographic digital data and/or map products (or series) produced and maintained \& Question 2: Current Age of Existing Geodata

Most of the Island countries are small in area and population as revealed by the figures for each of the countries in Table 1, 
where ' $\mathrm{x}$ ' indicates mapping at these scales. While there are a variety of scales of maps provided by each country, little information is available on the actual coverage or the age of the maps.

\section{Question 3 - Restrictions on Map Data Distribution}

Cook Is No

Solomon Is - No

Tonga - Yes

RMI - No

Vanuatu - No

Fiji - No

Question 4 - Sale of Maps: Are maps sold to the public free of charge and free to Government departments?

Cook Is: Sold to the public, not free, not freely available to Government departments. Users need to be registered to enable them to use the data for free.

Solomon Is - Maps sold to the public, not freely available and free of charge to stakeholders. A similar pricing is used as in Australia, but in local currency.

Tonga - Sold to public, not free and not free to stakeholders, pricing being trialled.

RMI - Free of charge to public and stakeholders

Vanuatu - Sold to public, free to stakeholders, not available online.

Fiji - Sold to public, free to stakeholders. Price in accordance to scales and file sizes.

\section{Question 5 - Updating Strategy}

Cook Is - mapping update program available.

Solomon Is -revision program across all scales

Tonga - mapping program available across scales with planned revision every 5 years depending on funding RMI - N/A

Vanuatu - complete revision of whole series

Fiji - revision program across all scales

Summary: Some island countries have a revision program, although only Tonga indicated that it aims for a 5 year revision cycle.

\section{Question 6 - Updating Methodology}

Cook Is - Field surveys, satellite images and crowd sourcing. Solomon Is - aerial photography for 1:5000 and larger, satellite images and for smaller of scales; $3^{\text {rd }}$ party data sources also used.

Tonga - field surveys

RMI - field surveys

Vanuatu - field surveys

Fiji - field surveys, aerial survey, photogrammetric

Summary: the majority of countries indicated that they updated their maps by field surveys, although subsequent questions indicate that satellite imagery is also available and presumably used for updating their smaller scale maps.

\section{Question 7 - In-house Capabilities of NMAs}

Cook Is - In-house and outsourcing from LINZ for updating $1: 25,000$.

Solomon Is - in-house

Tonga - in-house
RMI - N/A

Vanuatu - In-house

Fiji - In-house

\subsection{National Imagery Acquisition}

Question 8 - National Aerial Imagery Program

Cook Is. No national imagery capability.

Solomon Is - No national imagery capability, acquired from international programs, digital imagery used

Tonga - No national imagery capability, acquired internationally, no regular program

RMI - No national imagery capability, images acquired internationally, no regular program, analogue

Vanuatu - No national imagery capability, images acquired internationally, no regular program, digital imagery used.

Fiji - A national imagery program exists, flown internationally on a regular basis and currently analogue.

Summary: With the exception of Fiji, none of the countries has a regular imagery program. Imagery is collected for all countries by international contractors.

\section{Question 9 - Satellite Imagery Used by NMA}

All countries acquire satellite imagery from international satellites systematically or on an as needed basis.

\section{Question 10 - Use of Radar or Lidar}

Cook Is - No other imagery acquired

Solomon Is - No other imagery acquired

Tonga - Yes, airborne lidar is acquired on the main islands of Tongatapu \& Pangai - Haápi Island Resolution with $0.2 \mathrm{~m}$

RMI - No

Vanuatu - Yes, airborne lidar coverage only of some parts of main islands like Efate, Malekula and Santo for assessment of climate change

Fiji - No

Summary: generally airborne lidar data are acquired for specific locations in the island countries.

\section{Question 11 - Lidar DEM}

Airborne lidar DEMs are derived for specific limited areas.

\section{Question 12 - Orthophoto Program}

Cook Is - no.

Solomon Is $-1: 5000$ and 1:7500

Tonga - Yes, digital

RMI - No

Vanuatu - 1:5000 for 6 Provincial centers and the 2 main town Fiji $-1: 20,000$

Summary: There is some evidence of the production of orthophotos in some countries but not across all islands and there is no consistency in scales.

\section{Question 13 - National DEM}

Tonga and Vanuatu have a program for national DEM coverage.

\section{Question 14 - Interest in 3D technology by NMA}

Only Solomon Is and Fiji are currently interested 


\subsection{National surveying and cadastral coverage}

\section{Question 15 - Licensed Surveyors?}

Cook Is - Yes.

Solomon Is - Yes

Tonga - No

RMI - No

Vanuatu - Yes

Fiji - Yes

Question 16 - Responsibility for Cadastral Mapping and Cadastral Map Coverage

Cook Is - There is a national program undertaken by the private sector.

Solomon Is - Undertaken by NMA

Tonga - Undertaken by other Government department.

RMI - Undertaken by NMA

Vanuatu - Undertaken by NMA

Fiji - Undertaken by NMA, except for Registrar of Titles in the Attorney General's Office.

\section{Question 17 - Use of Cadastral Maps}

Uses are for Land registration, Titles, Conveyancing, Taxation, and Other, for all countries.

\section{Question 18 - Cadastral Maps and Geodetic Control}

Cook Is - WGS84

Solomon Is - International, GUX1 Astro

Tonga - Tonga Cadastral

RMI - A local coordinates system based on UTM zone 59 on false origin

Vanuatu - Local systems but wish to change to a global system Fiji - WGS 72 Spheroid

Summary - There is no consistency in the projection systems adopted by the various countries with several basing their mapping on local systems.

\section{Question 19 - Monumentation of Property Boundaries}

All countries use monumentation for boundaries.

\section{Question 20 - Updating of Cadastral Maps}

Cook Is - A court order from the Ministry of Justice for changes to the original boundaries will lead to updating.

Solomon Is - When surveys for new boundaries, subdivisions, extensions or combinations is been effected

Tonga - maintenance of the cadastral master plan

RMI - Field survey

Vanuatu - A cadastral database exists for all surveys throughout the country which is updated on a daily basis.

Fiji - Each new survey results in new plans which will be reflected in the cadastral maps

Summary - Generally the cadastral data is maintained and updated regularly, in some countries on a daily basis.

\section{Question 21 - Number of Cadastral Employees}

Cook Is - 7 surveyors in private sector and government.

Solomon Is -13 in private sector and government

Tonga -3 surveyors

RMI - 4 surveyors
Vanuatu - 14 government and private surveyors

Fiji - about 200

Summary -the number of surveyors reflects the populations in the different countries, but apart from Fiji there appears to be serious shortage of surveyors to undertake cadastral surveys in these countries, resulting in the cadastral system being poorly served.

\subsection{Organisation}

\section{Question 22 - National Funding for Mapping}

Cook Is - funded by Government

Solomon Is - No

Tonga - Yes

RMI - No

Vanuatu - Surveying and cadastral program - Government;

Mapping - Funding Agency

Fiji - Yes

Summary - most countries provide funding for mapping programs but some depend on funding agencies.

\section{Question 23 - Mapping Budget}

Summary - no country is able to provide details of budget for mapping. It seems that the level of funding is low.

\section{Question 24 - NMA staff}

Cook Is -4 staff

Solomon Is -5 mapping staff.

Tonga - About 14 drafting staff

RMI - 4

Vanuatu - 2

Fiji - about 90

Summary - as stated in Q21, apart from Fiji there are inadequate staff to undertake and revise mapping programs in most countries.

\section{Question 25 - Legal Status of Mapping}

Cook Is - No

Solomon Is - Yes, stipulated in the Ministry Corporate Plan. Strategic Plan, Annual Plans and Individual work plans

Tonga - Under the Land Acts, the Minister for Lands has the authority for cadastral maps

RMI - Surveys are governed by the Land Surveying Act which states that there must be a Board of Land Surveyor Examiners which shall consist of five ( 5 ) members and each must have qualification or background in surveying or other related fields such as civil engineer, architect and geography. The Surveyor General who shall be appointed by the Minister is charged with the general administration of the act. In ten years or so there has been no such Board, nor a register of land surveyors. The Office has been operated by unqualified persons.

Vanuatu - The Land Surveyor's Act mandates the Director of Lands, Survey and Registry to undertake the production of topographic mapping. Since independence in 1980, there has been assistance from the Australian Defence for the production of mapping for all islands.

Fiji - The Ministry of Lands and Mineral Resources is mandated by the government to capture, verify, approve and authorize the use of all data pertaining to mapping and surveying in Fiji. 
Summary - There is legislation in all countries mandating mapping and the management of the data, although some countries depend on aid programs to complete their mapping, while the program in RMI in not operational.

\section{Question 26 - Form of Map Products Supplied}

Cook Is - 60\% hardcopy, 20\% digital, 10\% downloaded and $10 \%$ by web services

Solomon Is $-85 \%$ hardcopy, $10 \%$ digital, $5 \%$ downloaded

Tonga $-100 \%$ hardcopy

RMI - N/A

Vanuatu - N/A

Fiji $-70 \%$ hardcopy, 25\% digital, 10\% downloaded

\section{Question 27 - Archival of Geodata}

Cook Is - Hardcopy and digital

Solomon Is - Ministerial server centralised under government ICT networking system

Tonga - Hard copies in storage, digital topographic \& GIS maps in server

RMI - N/A

Vanuatu - Digital archival for digital data and an archival for hard copy maps

Fiji - Hardcopies stored in the ministry and also in the National Archives and digital backed-up in servers

\section{CONCLUSIONS}

The paper gives a brief description of the map coverage in Oceania including the Australia federal government and states/territories, New Zealand and some Pacific Island countries. In comparison with the 1986 survey of mapping in Oceania, there have been significant increases in the percentage coverage of map scales investigated. The paper reveals that the current map coverages are estimated to be:

- $4.5 \%$ coverage for map scales at 1:10,000 and larger

- $26.7 \%$ coverage for map scales at 1:25,000

- $46.3 \%$ coverage for map scales at 1:50,000

- $96 \%$ coverage for map scales at 1:100,000

- $99 \%$ coverage for map scales at 1:250,000
All current maps in Australia and New Zealand are produced in digital form, but older maps were produced as hardcopies. As well, older maps in Australia are increasingly becoming out-ofdate without a schedule for their updating, while New Zealand has a regular update program. There is a need for further funding being provided for updating these maps. Current methods of mapping involve the latest technologies, including digital aerial cameras, satellite images where appropriate, and airborne lidar. The nationwide DEM is inadequate for many purposes, especially for the study of the effects of sea-level rises, and hence has to be supplemented by new higher density surveys.

The extent of map coverage in some Pacific Island countries is not well defined. Overall the availability of modern technologies, especially satellite images, digital aerial photography and airborne lidar, should enable the island countries to provide better map products in future, but this would depend on many occasions on foreign aid. There appear to be insufficient professionals in most countries to maintain the mapping programs. Given that many Pacific Island countries will be impacted by rising sea level in the future, better mapping of these countries is essential.

\section{References}

Konecny G, 2013 'The International Society for Photogrammetry and Remote Sensing (ISPRS) study on the status of mapping in the world, paper presented to Second High Level Forum on Global Geospatial Information Management, Doha, Qatar, 4 - 6 February 2013, pp1-23.

Marwick B 2013 'A Collaborative Framework to Support a National Land Information Infrastructure in Australia',

Master of Geomatic Engineering thesis, University of Melbourne, pp1-124.

The Geography of Oceania http://geography.about.com/od/specificplacesofinterest/a/oceani a.htm Accessed 26 March 2016.

\section{Acknowledgments}

The contributions of the Australian, New Zealand and Pacific Island mapping agencies which responded to the questionnaire are gratefully acknowledged. 